\title{
Reproductive patterns and pregnancy outcomes in women with congenital heart disease - a Swedish population-based study
}

\author{
Ann Josefsson, Kristina Kernell, Niels Erik Nielsen, Marie Bladh and Gunilla Sydsjö
}

\section{Linköping University Post Print}

N.B.: When citing this work, cite the original article.

This is the authors' version of the following article:

Ann Josefsson, Kristina Kernell, Niels Erik Nielsen, Marie Bladh and Gunilla Sydsjö, Reproductive patterns and pregnancy outcomes in women with congenital heart disease - a Swedish population-based study, 2011, Acta Obstetricia et Gynecologica Scandinavica, (90), 6, 659-665.

which has been published in final form at:

http://dx.doi.org/10.1111/j.1600-0412.2011.01100.x

Copyright: Informa Healthcare / Wiley-Blackwell http://eu.wiley.com/WileyCDA/Brand/id-35.html

Postprint available at: Linköping University Electronic Press http://urn.kb.se/resolve?urn=urn:nbn:se:liu:diva-69887 
Reproductive patterns and pregnancy outcomes in women with congenital heart disease - a Swedish population-based study

ANN JOSEFSSON, MD, PhD ${ }^{1}$, KRISTINA KERNELL, MD ${ }^{1}$, NIELS ERIK NIELSEN, MD, $\mathrm{PhD}^{2}$, MARIE BLADH, $\mathrm{MA}^{1} \&$ GUNILLA SYDSJÖ, $\mathrm{PhD}^{1}$

${ }^{1}$ Division of Obstetrics and Gynecology, Department of Molecular and Clinical Medicine, Faculty of Health Sciences, Linköping University, Linköping, Sweden and ${ }^{2}$ Division of Cardiovascular Medicine, Department of Medical and Health Sciences, Faculty of Health Sciences, Linköping University, Linköping, Sweden 


\begin{abstract}
Objective. To study women diagnosed with congenital heart disease (CHD) with respect to characteristics related to their own births, their subsequent likelihood of giving birth and the obstetric and neonatal outcomes of their pregnancies.

Design. Population-based register study.

Population. All women born 1973-1983 who were alive and living in Sweden at 13 years of age $(n=500245)$.

Methods. Women diagnosed with CHD ( $\mathrm{n}=2$ 216) were compared with women without CHD ( $n=492476$ ). A total of 188867 mother-firstborn-offspring pairs were identified and available for analysis.

Results. Mothers of women with CHD were more often older and single/unmarried. Women with CHD were more often born preterm or small-for-gestational age (SGA) than women without CHD, more likely to have been born with a cesarean section, to have given birth during the study period, and to be younger at the time of their first pregnancy. Women with CHD were also more prone to give birth to children preterm or SGA and their babies were more often delivered by cesarean section with a higher frequency of congenital abnormality. Conclusions. Women with CHD were more likely to have been born preterm or SGA and these outcomes were repeated in the next generation. Women with CHD should not be discouraged from pregnancy. Prenatal diagnostics should be discussed and offered to women with CHD as there is an increased risk for congenital abnormalities.
\end{abstract}

Key words: Congenital heart disease, reproduction, high-risk pregnancy 
Abbreviations: $C H D$, congenital heart disease; SGA, small-for-gestational age; $M B R$, Swedish Medical Birth Registry; TPR, Total Population Registry; NPR, National Patient Registry; BMI, body mass index.

\section{Conflict of interest}

The authors have stated explicitly that there are no conflicts of interest in connection with the article. 


\section{Introduction}

The incidence of congenital heart disease (CHD) is 5 - 8 per 1000 live-born infants (1). Reproductive patterns for women with CHD have not been well studied. In the past, the high mortality among these women often led to the recommendation that they should avoid pregnancy. Pregnant women with congenital heart disease are at increased risk for cardiac and neonatal complications, but the exact nature of risk factors for adverse outcomes has not, as yet, been fully defined (2-4). Most studies and current knowledge are based on clinical samples that included both women with CHD and women with acquired heart disease (5-7). Swedish population-based registries are prospectively collected and contain well-validated data. They therefore provide a unique opportunity to study the effect of congenital heart disease on reproductive pattern in a large cohort. Our aim was to investigate whether women diagnosed with CHD differed from those without CHD with respect to characteristics of their own births, their subsequent likelihood of giving birth, as well as obstetric and neonatal outcomes of their pregnancies.

\section{Material and Methods}

The Swedish Medical Birth Registry (MBR) was established in 1973 and covers approximately $99 \%$ of all births. The Registry contains a large number of items concerning pregnancy, delivery and pediatric neonatal examination, as well as certain maternal characteristics such as previous reproductive history (8). The Total Population Registry (TPR) contains information on births, deaths, marital status, as well as information on migrations, and country of origin for Swedish residents born abroad (9). The National Patient Registry (NPR) has been in use since 1964 and from 1987 onwards it covers all public, in-patient care in Sweden (10). The NPR continuously receives patient, hospital and administration data, including diagnosis, external cause of injury, poisoning and 
surgical procedures. The diagnoses in the NPR are based on the Swedish version of the World Health Organization International Classification of Diseases (ICD). ICD-8 (11) was used until 1986, ICD-9 (12) was used between 1987 and 1996, and ICD-10 (13) from 1997 onwards. The Causes of Death Register records information on all deceased persons registered in Sweden at the time of death (14). Using the Multi-Generation Register it is possible to identify the fathers of the children registered in the MBR and the TPR (15). Information on the educational level of the women in the study population as well as their parents was retrieved through of the Education Register and the Population and Housing Census 1970, respectively $(16,17)$.

All women born in 1973 - 1983 according to the MBR and the TPR, who were alive and still living in Sweden at 13 years of age served as the study population $(n=500245)$. Women with missing values on birthweight and/or gestational length were excluded ( $n=3360)$, as were those with extremely high or low birth weights compared to their length of gestation $(n=2$ 193). The exclusion procedure is explained elsewhere (18). The final cohort therefore consisted of 494692 women who were followed up until the end of 2006. During the study period, $4.3 \%$ of the women emigrated and $0.38 \%$ died. The 494692 women were then individually linked to the maternal personal identification numbers for births occurring in the MBR before 2006 (the first birth occurred in 1987). Thus, at the time of the study, the maximum maternal age was 33 years. A total of 189819 mother-firstborn-offspring pairs were identified, of which 912 pairs were excluded due to missing values on the child's birthweight and/or gestational length, and an additional 40 due to the children having extremely high birthweights given the length of their gestation or an unlikely length of gestation (18). Thus, 188867 mother-firstborn-offspring pairs were available for analysis. 
CHD was defined as the women having one or more of the following three-digit-level codes: ICD-8: 746 or 747, ICD-9: 745-747, ICD-10: Q20-Q26. These 'cases' were identified through both the MBR and NPR.

We divided the congenital heart defects into complex and simple. Complex defects were defined as truncus arteriosus, transposition of the great arteries, tetralogy of Fallot and singleventricle defects. Simple defects were defined as isolated valve disease, isolated atrial or septal defect, coarctation of the aorta or persistent ductus arteriosus.

Information on socioeconomic and other background characteristics of both the studied women and their parents was retrieved from the registries (19). We also had information about the parents' educational levels in 1985, their country of origin, as well as the mothers' marital status, parity, and age at the time of giving birth (i.e. 1973-83). For the studied women we had information on several birth-related variables such as birthweight, gestational length, instrumental delivery, cesarean section, and whether the women were the result of a twin birth. Preterm birth was defined as birth before 37 completed weeks of gestation, and smallfor-gestational age (SGA) was defined as a birthweight $<-2$ standard deviations of the mean birthweight for the gestational length according to Swedish external standards from 1996 (20). Furthermore, we were able to retrieve information on the women's educational levels and marital status at 25 years of age. For the women who had become mothers during the study period we also had information on cohabitation status, body mass index (BMI) and smoking habits during early pregnancy, as well as age when giving birth.

Women diagnosed with congenital heart disease were compared with those not diagnosed with the condition by means of the Chi-squared test and the $t$-test; the results of these analyses are presented in Tables 2-6. The data were also modeled through Cox's proportional hazards model to estimate the effect of congenital heart disease on the women's subsequent likelihood of giving birth. The time-dimension was defined as age; subjects exited from risk when they 
gave birth to the first child, emigrated for the first time, died or reached the end of follow-up, whichever took place first. Both crude and adjusted hazard ratios and corresponding $95 \%$ confidence intervals were calculated. Adjustments were made for parental socioeconomic characteristics (Table 2).

In addition to the Chi-squared tests presented in Tables 3 and 5, differences between the women who were diagnosed with congenital heart disease and those who were not, were estimated by means of multiple logistic regression analysis, controlling for background variables presented in Tables 2 and 4, and the odds ratios and corresponding confidence intervals were calculated. By this method we were able to account simultaneously for the combined effect of the studied variables. However, as the differences between these analyses and the Chi-squared tests presented in the tables are not substantial; we chose not to present the results of these additional analyses.

This study was approved by the Human Research Ethics Committee, Faculty of Health Sciences, Linköping University.

\section{Results}

Of the 494692 women born in 1973-1983, $2216(0.45 \%)$ had been diagnosed with CHD and of these, 197 (8.9\%) had a complex CHD (Table 1). Table 2 presents the socioeconomic characteristics of the parents and shows that mothers of the women with CHD more often were older and single or unmarried. Women diagnosed with CHD were more likely to have been born preterm or SGA than women not diagnosed with CHD (Table 3).

The women with CHD were also more likely to have been delivered by cesarean section, and more often the result of a twin birth. All associations remained significant when simultaneously including all categorical variables in Table 3 as well as the socioeconomic characteristics presented in Table 2 in the same model (data not shown). Among the women 
in the study cohort, 188867 had become mothers before the end of 2006. Table 4 presents birth rates for women diagnosed with different CHD as well as $p$-values for the comparison of women diagnosed with the specific CHD compared to all other women in the study (not diagnosed with the specific CHD, their corresponding birth rate being 38.4\%). As can be seen in Table 4, women diagnosed with CHD have significantly lower birth rates compared to women not diagnosed with the specific CHD except from single ventricle, congenital aortic valve stenosis, and coarctation of the aorta, where no differences were found. However, when adjustments were made for the parental socioeconomic characteristics presented in Table 2, women who were diagnosed with CHD were significantly more likely to have given birth during the study period; Hazard ratio $=1.140(95 \%$ confidence interval: $1.058-1.228), p=$ 0.001 (data not shown).

Table 5 shows that women with CHD were younger at the time of their first pregnancy. There were no other differences concerning socioeconomic characteristics, BMI, smoking, hypertension or diabetes during pregnancy between the groups of women. In Table 6 , delivery-related data of the studied women's firstborn children are presented. Women who themselves were diagnosed with CHD were more likely to give birth to children born preterm, SGA and via cesarean section. Women with CHD were also more likely to give birth to a child with a congenital anomaly $(p<0.001)$. There were no significant differences regarding these variables among those diagnosed with simple and complex CHD, respectively. When the variables in Table 6 (i.e. preterm birth, SGA, cesarean section, and congenital anomalies) were analyzed simultaneously, all associations were still evident (data not shown). Within the first year after delivery there were 26 maternal deaths. None of these women had a CHD. 


\section{Discussion}

In this large national population-based study we found that women with CHD were more likely to have been born preterm or SGA than women without CHD. Women with CHD were also more likely to have been born with a cesarean section, which is in accordance with earlier findings (21). There was a difference in the likelihood of CHD women giving birth, as women with CHD more often were younger first-time mothers. Women with CHD were more prone to give birth prematurely and to give birth to SGA children. There was also an overrepresentation of children with congenital abnormalities born to mothers with CHD. This is in line with the results from other recent studies on pregnancy outcome in women with CHD (4, 7, 22-24). Yet, there are to our knowledge no large population-based studies in the literature that have been able to compare mothers with CHD with all those who do not suffer from CHD.

Since maternal deaths connected with pregnancy and delivery are reported in the literature for groups of women with CHD, the results in this study where no maternal deaths were found among women with CHD, are of special interest. However, this finding may reflect better clinical management of these women because of greater awareness of the risks that pregnancy posed for them. Preconception counseling is often available now, and many clinics have a multidisciplinary management system for pregnant women with CHD, a system in which different specialists (such as obstetricians, cardiologists, anesthesiologists) work closely together.

The study did not show any difference between women with simple CHD and complex CHD, which was somewhat surprising. However, this might be explained by the sample size or by the relatively young age of the study population. Another possible explanation is that we only included the women's firstborn child. 
Generally, the offspring of women with CHD have a 5-8 \% incidence of CHD $(25,26)$. In this study, women with CHD had a high risk of giving birth to a child with a congenital abnormality. Women with a complex CHD had an almost threefold higher risk of giving birth to a child with a congenital abnormality than women in the normal population. We were unable to investigate the proportion of CHD among these children with a congenital abnormality due to lack of data in the registries. However, it is important to bear in mind that for the newborn child to receive a diagnosis of CHD in NPR, the defect has to be diagnosed before the mother and child are discharged after delivery and it is well-known that in many children the heart defects are diagnosed at a later stage. Furthermore, it was not our purpose to examine the incidence of children with CHD in our population, but to compare the reproductive patterns of women with and without CHD. Finally, NPR did not have total coverage for the whole of Sweden until 1987, but we have tried to get as complete data as possible by including all counties that had reported before 1987.

The advantage of register studies is the large number of individuals available for evaluation and the absence of selection bias. A large number of individuals makes it possible to divide the study population into subgroups with sufficient numbers in each stratum and gives high statistical power. A drawback is the sometimes low validity of information. We used ICD codes as a definition of CHD. It is obvious, given the large size of the study and the numbers of health care givers involved, that the criteria for diagnosing CHD may not be uniform across the study population. The major limitation of this study is the paucity of clinical data concerning women with CHD.

Congenital heart defects are the most common congenital abnormality and many if not most have been successfully treated in the past several decades. Most obstetricians will clinically encounter pregnant women with a history of CHD. Also, the population with a history of CHD is different from the population of women with functional or acquired heart disease. 
Therefore, further large studies on co-morbidity and extra-cardiac features frequently associated in patients with CHD, surgical interventions and subsequent pregnancies are needed in women with CHD to reach a more thorough understanding. In conclusion, this large population-based register study has shown that women with CHD are more likely to have been born preterm or SGA, and themselves to give birth to children preterm, SGA and with congenital abnormalities compared with women without CHD. This is important to bear in mind when advising women with CHD about pregnancy. Prenatal diagnostics should be discussed and offered women with CHD. Antenatal health care in collaboration with specialists in obstetrics, cardiology and anesthesiology should be provided in order to minimize the risks during pregnancy and delivery.

\section{Funding}

This study was supported by grants from The Health Research Council of the Southeast of Sweden and ALF, County Council of Östergötland. 


\section{References}

1. Cunningham, MacDonald, Gant, Leveno, Gilstrap, Hankins, Clark. Appleton \& Lange (eds). Williams Obstetrics 20th edn. Stamford, CT:Appleton \& Lange.1997:1088.

2. Earing MG, Webb GD. Congenital heart disease and pregnancy: maternal and fetal risks. Clin Perinatol. 2005;32:913-9.

3. Reimold SC, Rutherford JD. Clinical practice. Valvular heart disease in pregnancy. N Engl J Med. 2003;349:52-9.

4. Siu SC, Sermer M, Colman JM, Alvarez AN, Mercier LA, Morton BC, et al. Cardiac Disease in Pregnancy (CARPREG) Investigators. Prospective multicenter study of pregnancy outcomes in women with heart disease. Circulation. 2001;104:515-21.

5. Curtis S, Marsden-Williams J, Sullivan C, Sellers SM, Trinder J, Scrutton M, Stuart AG. Current trends in the management of heart disease in pregnancy. Int J Cardiol. 2009; 133:62-9.

6. Avila WS, Rossi EG, Ramires JA, Grinberg M, Bortolotto MR, Zugaib M, et al. Pregnancy in patients with heart disease: experience with 1,000 cases. Clin Cardiol. $2003 ; 26: 135-42$

7. Khairy P, Ouyang DW, Fernandes SM, Lee-Parritz A, Economy KE, Landzberg MJ. Pregnancy outcomes in women with congenital heart disease. Circulation. 2006;113:517-24.

8. Centre for Epidemiology, National Board of Health and Welfare. The Swedish Medical Birth Registry; A summary of content and quality (Article no. 2003-112-3) (http://www.sos.se/fulltext/112/2003-112-3/2003-112-3.pdf). Stockholm: National Board of Health and Welfare, 2003.

9. Statistics Sweden. A new Total Population Registry system. More possibilities and better quality. (Serial no. 2002:2). Örebro: Statistics Sweden, 2002. 
10. Centre for Epidemiology, National Board of Health and Welfare. In-patient diseases in Sweden 1987-2001 (Article no. 2003-42-8) (http://www.sos.se/fulltext/42/2003-428/2003-428.pdf). Stockholm: National Board of Health and Welfare, 2003.

11. Centre for Epidemiology, National Board of Health and Welfare. The Swedish version of 8th revision of WHO's International Classification of Diseases (http://www.sos.se/epc/klassifi/FILER/KS68.pdf). Stockholm: National Board of Health and Welfare, 1968.

12. Centre for Epidemiology, National Board of Health and Welfare. The Swedish version of 9th revision of WHO's International Classification of Diseases (http://www.sos.se/epc/klassifi/FILER/klass87.pdf). Stockholm: National Board of Health and Welfare, 1987.

13. Centre for Epidemiology, National Board of Health and Welfare. The Swedish version of 10th revision of WHO's International Classification of Diseases (http://www.sos.se/epc/klassifi/ksh97kap.htm). Stockholm: National Board of Health and Welfare, 1997.

14. Centre of Epidemiology, National Board of Health and Welfare. Causes of Death 2001. (http://www.sos.se/FULLTEXT/42/2003-42-5/2003-42-5.pdf). Stockholm: National Board of Health and Welfare, 2003.

15. Statistics Sweden. Multi-generation registry 2002; a description of contents and quality (Serial no. 2003:5). Örebro: Statistics Sweden, 2003.

16. Statistics Sweden. Population and Housing Census 1970 (SOS). Part 12. Report on the planning and processing of the Population and Housing Census 1970. Stockholm: National Central Bureau of Statistics, 1974.

17. Statistics Sweden. Educational Attainment of the Population 2002. (Publication no. UF0506). (http://www.scb.se). Örebro: Statistics Sweden, 2003. 
18. Ekholm K, Carstensen J, Finnstrom O, Sydsjo G. The probability of giving birth among women who were born preterm or with impaired fetal growth: A Swedish population based registry study. Am J Epidemiol. 2005;161:725-33.

19. Statistics Sweden. Population and housing census 1970. Part 13. Economic activity and education. Definitions, comparability, development, etc. Stockholm: National Central Bureau of Statistics, 1975.

20. Marsal K, Persson PH, Larsen T, Lilja H, Selbing A, Sultan B. Intrauterine growth curves based on ultrasonically estimated foetal weights. Acta Paediatr. 1996;85:843-8.

21. Cedergren MI, Kallen B. Obstetric outcome of 6346 pregnancies with infants affected by congenital heart defects. Eur J Obstet Gynecol Reprod Biol. 2006;125:211-216.

22. Uebing A, Gatzoulis MA, von Kraisenberg C, Kramer HH, Strauss A. Congenital heart disease in pregnancy. Dtsch Arztebl Int. 2008;105:347-54.

23. Drenthen W, Pieper PG, Roos-Hesselink JW, van Lottum WA, Voors AA, et al. Outcome of pregnancy in women with congenital heart disease: a literature review. $\mathrm{J}$ Am Coll Cardiol. 2007;49:2303-11.

24. Yap S-C, Drenthen W, Pieper PG, Moons P, Mulder BMJ, Vliegen HW, et al. Pregnancy outcome in women with repaired versus unrepaired isolated ventricular septal defect. BJOG. 2010;117:683-9.

25. Siu SM, Colman JM, Sorensen S, Smallhorn JF, Farine D, Amankwah KS, et al. Adverse neonatal and cardiac outcomes are more common in pregnant women with cardiac disease. Circulation. 2002;105:2179-84.

26. Romano-Zelekha O, Hirsh R, Blieden L, et al. The risk for congenital heart defects in offspring of individuals with congenital heart defects. Clin Genet. 2001;59:325-9. 
Table 1. Distribution of congenital heart defects among 494692 women born 1973-1983.

Diagnosis

\section{Complex}

Truncus arteriosus 27

Transposition of the Great Arteries 81

Tetralogy of Fallot 105

Single ventricle 41

\section{Simple}

Ventricular Septal Defect

Atrial Septal Defect

Endocardial cushion-defect/

Atrioventricular septal defect

Tricuspid Valve Defect

Mitral Valve Defect 95

Pulmonary Valve Defect 239

Congenital Aortic Valve Stenosis 82

Patent Arterial Duct 536

Coarctation of the Aorta 163

Anomalies of the Pulmonary Artery 84

Anomalies of the Great Veins 88

Great vessels defects 216

Other heart defects 868

Other anomalies of the Aorta 66

Non-specified anomalies of the Heart or Great Vessels 535

Total 2216 Each person may have more than one CHD diagnosis. 
Table 2. Socioeconomic characteristics of the parents of the studied women ${ }^{\mathrm{a}}$.

\begin{tabular}{|c|c|c|c|c|c|}
\hline & \multicolumn{4}{|c|}{ Congenital heart disease } & \multirow[b]{3}{*}{$p^{\mathrm{b}}$} \\
\hline & \multicolumn{2}{|c|}{ Yes } & \multicolumn{2}{|c|}{ No } & \\
\hline & $\mathrm{n}$ & $\%$ & $\mathrm{n}$ & $\%$ & \\
\hline Mother's educational level & & & & & 0.349 \\
\hline Missing $^{c}$ & 162 & 7.3 & 32645 & 6.6 & \\
\hline $9-10$ years & 652 & 29.4 & 140891 & 28.6 & \\
\hline $11-13$ years & 901 & 40.7 & 207790 & 42.2 & \\
\hline$\geq 14$ years & 501 & 22.6 & 111150 & 22.6 & \\
\hline Father's educational level & & & & & 0.728 \\
\hline Missing $^{\mathrm{c}}$ & 159 & 7.2 & 36866 & 7.5 & \\
\hline $9-10$ years & 716 & 32.3 & 155421 & 31.6 & \\
\hline $11-13$ years & 889 & 40.1 & 196088 & 39.8 & \\
\hline$\geq 14$ years & 452 & 20.4 & 104101 & 21.1 & \\
\hline Mother's marital status & & & & & $<0.001$ \\
\hline Married & 1496 & 67.5 & 341422 & 69.3 & \\
\hline Divorced/widow & 608 & 27.4 & 133875 & 27.2 & \\
\hline Unmarried & 112 & 5.1 & 17179 & 3.5 & \\
\hline Mother's age & & & & & $<0.001$ \\
\hline $13-19$ years & 137 & 6.2 & 27445 & 5.6 & \\
\hline 20-26 years & 907 & 40.9 & 217864 & 44.2 & \\
\hline 27-33 years & 876 & 39.5 & 197316 & 40.1 & \\
\hline$\geq 34$ years & 296 & 13.4 & 49851 & 10.1 & \\
\hline Mother's parity & & & & & 0.381 \\
\hline No previous children & 920 & 41.5 & 208996 & 42.4 & \\
\hline Previous children & 1296 & 58.5 & 283480 & 57.6 & \\
\hline Parent's country of origin & & & & & 0.132 \\
\hline Both Nordic & 2026 & 91.4 & 454467 & 92.3 & \\
\hline One or both non-Nordic & 190 & 8.6 & 38009 & 7.7 & \\
\hline
\end{tabular}

a Analyses performed on all 494692 women in the study cohort whose parents could be identified through the registries. All variables were measured at the time of the studied women's birth (i.e. in 1973-83).

b Chi-squared test.

c This group consists of a greater proportion of women born to young and/or non-Nordic parents and to parents who immigrated later than 1970 and is therefore included as a separate category $(17,18)$. 
Table 3. Characteristics related to the women's own births in 1973-83 ${ }^{\mathrm{a}}$.

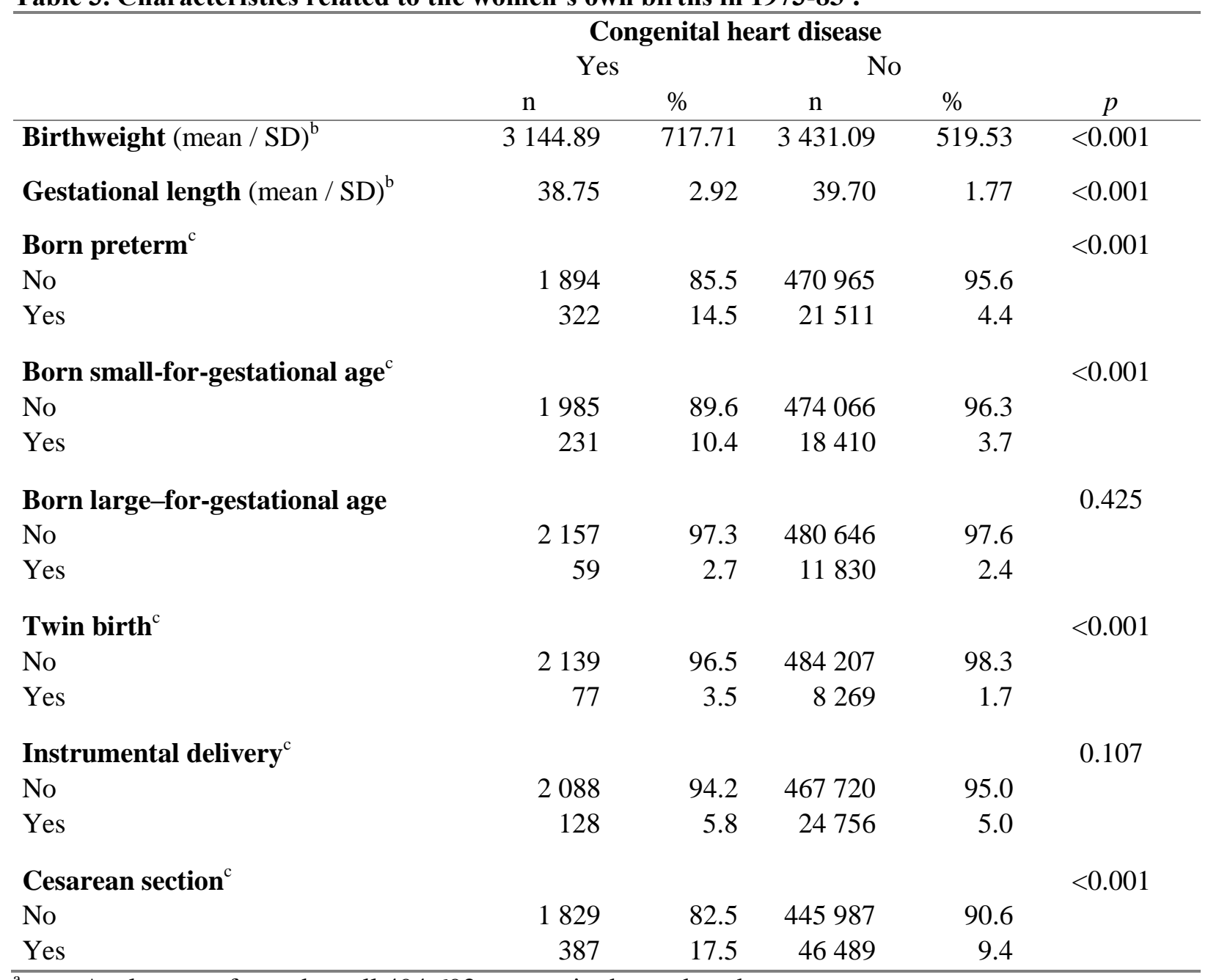

a Analyses performed on all 494692 women in the study cohort.

b Student's $t$-test.

c Chi-squared test. 
Table 4. Birth-rates for women diagnosed with CHD.

\begin{tabular}{|c|c|c|c|}
\hline \multirow[t]{2}{*}{ Diagnosis present } & \multicolumn{2}{|c|}{ Diagnosed $^{\mathrm{a}}$} & \multirow{2}{*}{$p$-value ${ }^{\mathrm{b}}$} \\
\hline & $\mathrm{n}$ & $\%$ & \\
\hline Truncus arteriosus & 5 & 18.5 & 0.034 \\
\hline $\begin{array}{l}\text { Transposition of the Great } \\
\text { Arteries }\end{array}$ & 22 & 27.2 & 0.038 \\
\hline Tetralogy of Fallot & 26 & 24.8 & 0.004 \\
\hline Single ventricle & 10 & 24.4 & 0.066 \\
\hline Ventricular Septal Defect & 222 & 32.8 & 0.003 \\
\hline Atrial Septal Defect & 187 & 32.0 & 0.001 \\
\hline $\begin{array}{l}\text { Endocardial cushion } \\
\text { defect/Atrioventricular } \\
\text { septal defect }\end{array}$ & 20 & 14.0 & 0.000 \\
\hline Tricuspid Valve Defect & 10 & 19.2 & 0.005 \\
\hline Mitral Valve Defect & 27 & 28.4 & 0.046 \\
\hline Pulmonary Valve Defect & 56 & 23.4 & 0.000 \\
\hline $\begin{array}{l}\text { Congenital Aortic Valve } \\
\text { Stenosis }\end{array}$ & 31 & 37.8 & 0.916 \\
\hline Patent Arterial Duct & 159 & 29.7 & 0.000 \\
\hline Coartation of the Aorta & 51 & 31.3 & 0.063 \\
\hline Other heart defects & 171 & 26.3 & 0.000 \\
\hline Great vessels defects & 55 & 25.5 & 0.000 \\
\hline Total & 697 & 30.7 & 0.000 \\
\hline
\end{tabular}

a Each person may have more than one CHD diagnosis. Compared to all other women in the study cohort. 
Table 5. Socioeconomic characteristics as well as BMI, smoking, hypertension and diabetes at the time of the studied women's own pregnancies ${ }^{\mathrm{a}}$.

\begin{tabular}{|c|c|c|c|c|c|c|c|}
\hline & & & nital l & disea & & & \\
\hline & & nplex & & & & HD & \\
\hline & $\mathrm{n}$ & $\%$ & $\mathrm{n}$ & $\%$ & $\mathrm{n}$ & $\%$ & $p^{\mathrm{b}}$ \\
\hline $\mathrm{Age}^{\mathrm{c}}$ & & & & & & & $0.011^{1}$ \\
\hline 13-19 years & 3 & 6.4 & 30 & 4.7 & 8204 & 4.4 & $0.587^{2}$ \\
\hline $20-24$ years & 19 & 40.4 & 224 & 34.8 & 55338 & 29.4 & $0.008^{3}$ \\
\hline$\geq 25$ years & 25 & 53.2 & 390 & 60.6 & 124634 & 66.2 & \\
\hline Educational level $^{\mathrm{c}}$ & & & & & & & $0.251^{1}$ \\
\hline $9-10$ years & 6 & 12.8 & 91 & 14.1 & 24018 & 12.8 & $0.380^{2}$ \\
\hline $11-13$ years & 30 & 63.8 & 372 & 57.8 & 104630 & 55.6 & $0.253^{3}$ \\
\hline$\geq 14$ years & 10 & 21.3 & 178 & 27.6 & 58368 & 31.0 & \\
\hline Missing & 1 & 2.1 & 3 & 0.5 & 1160 & 0.6 & \\
\hline Marital status $^{c}$ & & & & & & & $0.421^{1}$ \\
\hline Married & 38 & 80.9 & 538 & 83.5 & 159976 & 85.0 & $0.633^{2}$ \\
\hline Unmarried & 9 & 19.1 & 106 & 16.5 & 28200 & 15.0 & $0.296^{3}$ \\
\hline Smoking habits ${ }^{\mathrm{c}}$ & & & & & & & $0.181^{1}$ \\
\hline Not smoking & 39 & 83.0 & 554 & 86.0 & 165550 & 88.0 & $0.563^{2}$ \\
\hline Smoking & 8 & 17.0 & 90 & 14.0 & 22626 & 12.0 & $0.129^{3}$ \\
\hline BMI $^{\mathrm{c}}$ & & & & & & & $0.847^{1}$ \\
\hline$<20$ & 26 & 55.3 & 376 & 58.4 & 107416 & 57.1 & $0.715^{2}$ \\
\hline $20-24.9$ & 8 & 17.0 & 127 & 19.7 & 37682 & 20.0 & $0.833^{3}$ \\
\hline $25-29.9$ & 3 & 6.4 & 37 & 5.7 & 12040 & 6.4 & \\
\hline $30-34.9$ & 0 & 0.0 & 9 & 1.4 & 3891 & 2.1 & \\
\hline$\geq 35$ & 0 & 0.0 & 5 & 0.8 & 1341 & 0.7 & \\
\hline Missing & 10 & 21.3 & 90 & 14.0 & 25806 & 13.7 & \\
\hline Hypertension & & & & & & & $0.411^{1}$ \\
\hline No & 47 & 100.0 & 634 & 98.4 & 186120 & 98.9 & $0.389^{2}$ \\
\hline Yes & 0 & 0.0 & 10 & 1.6 & 2056 & 1.1 & $0.262^{3}$ \\
\hline Diabetes & & & & & & & $0.175^{1}$ \\
\hline No & 47 & 100 & 638 & 99.1 & 187326 & 99.5 & $0.506^{2}$ \\
\hline Yes & 0 & 0.0 & 6 & 0.9 & 850 & 0.5 & $0.070^{3}$ \\
\hline Analyses perf & 188 & womer & o had & ne mot & ers. & & \\
\hline Chi-squared te & & & & & & & \\
\hline The variables & ed a & e time o & gnancy & & & & \\
\hline Overall compe & & & & & & & \\
\hline Comparison b & 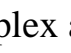 & simple. & & & & & \\
\hline Comparison b & & & & & & & \\
\hline
\end{tabular}


Table 6. Delivery-related characteristics of the studied women's firstborn children ${ }^{\text {. }}$

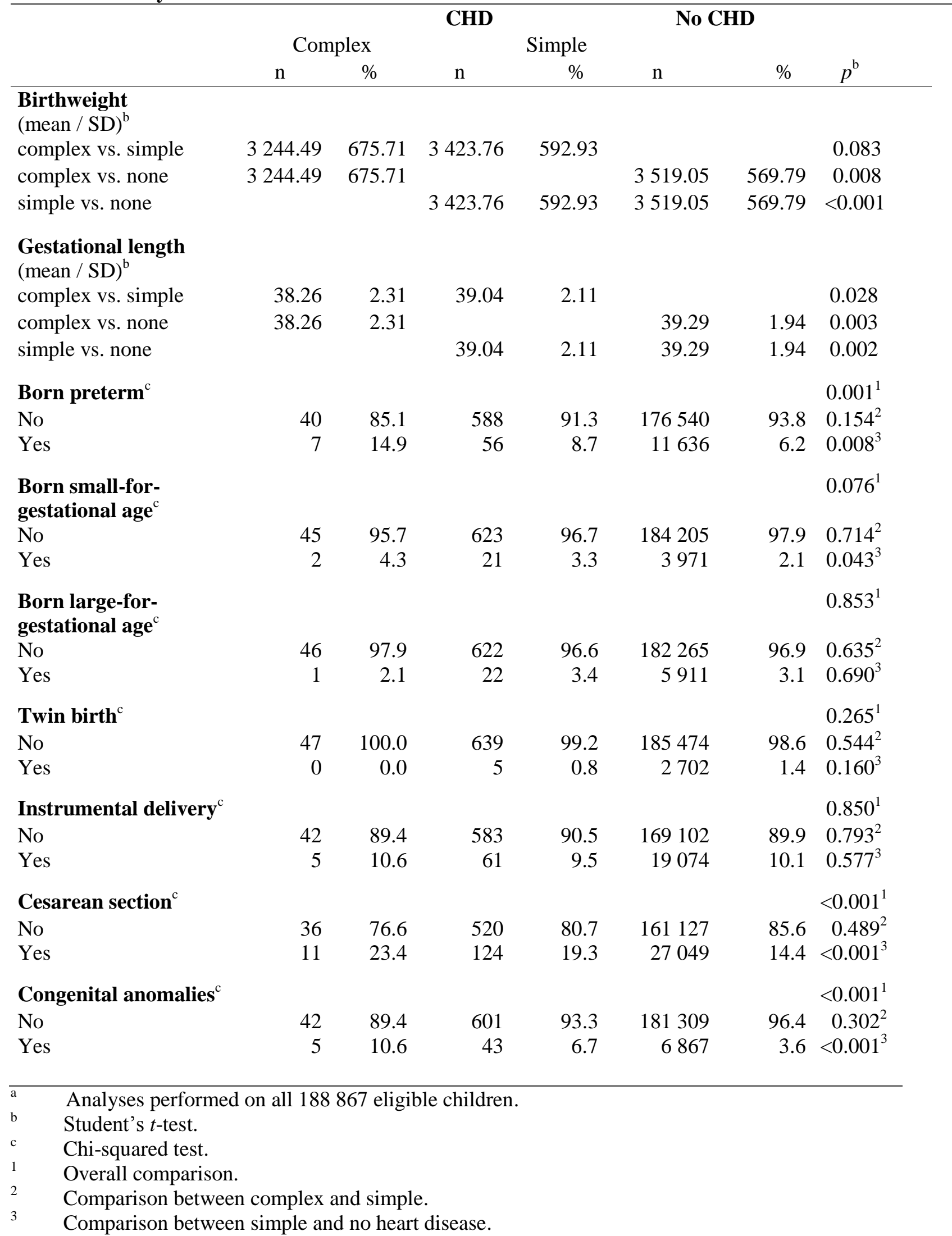

